http://dx.doi.org/10.30681/23588403v12i030724

\title{
POLISSEMIA E CAMPOS SEMÂNTICOS: UM ESTUDO SOBRE EXTENSÕES DE SIGNIFICADOS DAS PREPOSIÇÕES DE EIXO DE TRAJETÓRIA
}

\author{
Daiana do Amaral JEREMIAS (UFSC) ${ }^{1}$
}

Data de recebimento: $25 / 02 / 2018$

Aceite: 18/04/2018

Resumo: Esse artigo faz uma descrição do fenômeno da polissemia nas preposições 'de' e 'para' do português brasileiro, a partir de uma perspectiva localista de campos semânticos de Jackendoff (1983). Em uma concepção léxico-cognitiva, as preposições são itens polissêmicos, pois uma única preposição pode atribuir diferentes significados ao seu complemento ou objeto de referência, e esses significados são extensões de uma representação prototípica espacial de trajetória. Com isso, propomos que a projeção localista, presente no uso das preposições, é um reflexo do que incorporamos do mundo físico, ou seja, movimento corporal, orientação espacial e a nossa interação com os objetos, para nossa realidade linguística.

Palavras-chave: Campos Semânticos; Eixo de Trajetória; Polissemia; Preposição.

Abstract: This paper presents the polysemy of prepositions 'from' and 'to' of Brazilian Portuguese from a localist perspective of semantic fields. Namely, in a lexico-cognitive approach, the prepositions are polysemic items, because a single preposition can attribute distinct meanings to its complement or object of reference, and these meanings are extensions of a prototypical spatial representation of a trajectory. So, we propose that the localist projection, present in the use of prepositions, is a reflex of what we incorporate from the physical world to our linguistic reality, that is, corporal movement, spatial orientation and our interaction with objects.

Keywords: Semantic fields.Trajectory Ax. Polysemy.Preposition.

\section{Introdução}

Nas produções científicas, principalmente aquelas que se dedicam ao estudo das classes de palavras, encontramos o estudo das preposições com foco em classificações funcionalistas e formalistas. Nesse artigo, temos como proposta, fazer uma descrição de alguns usos das preposições 'de' e 'para' do português brasileiro enquanto itens polissêmicos e altamente esquemáticos. Daremos um diferente tratamento no estudo dessas partículas,

\footnotetext{
${ }^{1}$ Doutoranda do programa de pós-graduação em Linguística da Universidade Federal de Santa Catarina. Cidade Florianópolis/Santa Catarina. email: daianaah@hotmail.com.
} 
elevando sua função como fundamental na arquitetura básica da nossa mente. Para tanto, adotaremos a perspectiva localista de Jackendoff (1983, 1999), modelo teórico que se inscreve na vertente da linguística cognitiva.

Diferentemente do que tradicionalmente encontramos, propomos que essas duas preposições podem atribuir diferentes sentidos ao seu complemento ou objeto de referência, e esses sentidos estão ligados esquematicamente através de uma representação espacial de trajetória. Nessa orientação, temos como objetivo fazer uma análise de alguns exemplos dos diferentes usos dessas preposições e de como eles podem ser explicados por uma única abordagem locacional. Aqui, focaremos em casos os quais as preposições apresentam alguma relação com uma representação espacial, tanto em nível prototípico como em nível pseudo espacial.

Nosso trabalho está organizado da seguinte maneira: apresentaremos, primeiramente, um panorama geral dessas preposições e, em seguida, descrevemos quais processos cognitivos relacionados à polissemia estão envolvidos na representação espacial desses itens. Dentre esses processos, trataremos da experiência corporificada, um processo empírico cognitivo que viabiliza a compreensão do uso conceptual das preposições no âmbito locacional. Após essas apresentações, buscaremos organizar as representações conceituais e espaciais em campos semânticos distintos, corroborando uma perspectiva localista.

De modo a expressar e identificar os usos dessas preposições, apresentaremos alguns exemplos os quais os sentidos de 'de' e 'para' estão aparentemente expandidos. Em seguida, organizaremos os significados que depreendemos de cada uma delas dentro dos campos semânticos Identificacional, Possessional e Temporal, propostos por Jackendoff (1983). Com isso, analisaremos e enquadraremos, conforme equivalência de significados, as ideias de "identificação", "posse" e "tempo".

Na abordagem de campos semânticos de Jackendoff (1983), compreendemos que as preposições podem ser descritas como polissêmicas, pois uma única preposição pode atribuir diferentes significados que, através de interpretação metafórica, podem ser compreendidos como extensão de um significado prototipicamente espacial. Para outros teóricos, tais como Tyler e Evans (2003), Taylor (2003), Fauconnier e Turner (2003) entre outros, a polissemia acontece quando os significados distintos, de um mesmo item lexical, possui relação entre si em algum nível de representação. A princípio, alguns usos de preposições já apresentam um significado espacial de base, no entanto, Jackendoff (1983) estabelece campos semânticos abstratos (aplicável a todas as línguas) que estão cognitivamente ligados, possibilitando, que, 
no português brasileiro, verifiquemos que muitos dos significados das preposições 'de' e 'para' sejam, de certo modo, relacionados conceptualmente à representação espacial de trajetória.

\section{As preposições 'de' e ' para' do português brasileiro: um panorama do cenário linguístico}

No conjunto total das preposições do português brasileiro, as preposições 'de' e 'para' estão entre as preposições mais usadas pelos falantes (Ilari et al., 2008). Se levarmos em conta a estatística apontada pelos autores, estaremos corroborando a ideia defendida por Pinker (2007) de que quanto mais um item de uma língua é usado, mais polissêmico ele é.

Segundo classificações cognitivas, prototipicamente, as preposições têm como principal função localizar no espaço eventos, objetos, pessoas ou animais, ou seja, elas atuam como operadores de predicação (CASTILHO, 2010 p. 584). Nessa relação de predicar, chama-se Figura cada objeto ou evento que a preposição localiza, e Ponto de referência cada objeto ou evento que serve de "local" para a figura.

Atuando como predicadores de espaço, conseguimos identificar o sentido de base das preposições quando elas expressam espacialmente categorias primitivas de movimento, deslocamento, trajeto inicial ou final. Por exemplo, na sentença “Eu saí do Rio de Janeiro”, temos, inicialmente, um percurso onde a preposição "de" demarca o ponto de origem do evento "sair". Corroborando ao princípio natural de economia da língua (RICOUER, 2005), arguimos que muitos dos significados, estabelecidos pelas preposições, expandiram-se de uma raiz originalmente espacial para outras noções, as quais no português brasileiro podem ser classificadas como de especificação, temporal, posse, entre outros; portanto, atestam uma natureza polissêmica dos sentidos que denotam.

A polissemia atesta o caráter aberto da textura das palavras: uma palavra é isto que tem vários sentidos e que ainda pode adquirir novos. Portanto, é um traço descritivo da significação que introduz a teoria das mudanças de sentidos, a saber, que para um nome pode haver mais de um sentido e, para um sentido mais de um nome. (RICOUER, 2005, p. 182).

Numa ótica cognitivista, essa extensão de sentidos é um resultado das experiências corpóreas do falante com o meio, na qual novos valores de significados são repercutidos no léxico de uma língua específica (LAKOFF; JOHNSON, 1980). Segundo Croft \& Cruse (2004), “[...] unidades polissêmicas são derivadas da mesma fonte lexical, sendo o resultado 
de processos de extensão, tais como metáfora ou metonímia” (p. 111)2. Assim, para se compreender um significado polissêmico das preposições 'de' e 'para', individualmente, recorremos a uma interpretação metafórica e identificamos a relação com o significado primitivo espacial. Segundo Jackendoff (1983), quando não há uma relação prototipicamente espacial entre uma figura e um objeto de referência, chama-se pseudo espaço o lugar localizado pela preposição. Ao adotar essa concepção, pressupõe-se que há uma estabilização dos significados prototípicos e, a partir disso, intuitivamente o falante faz uma expansão inconsciente e conceitual dos significados originais.

\subsection{Polissemia nas preposições 'de' e 'para'}

A polissemia é um fenômeno que ocorre quando um item na língua tem mais de um significado e, esses significados apresentam relação entre si (CANÇADO, 2012). Apesar das diferentes atribuições, em decorrência de contextos de uso distintos, estes sentidos estão interligados através de uma representação espacial, pois as preposições têm uma função básica de localizar objetos no espaço (PINKER, 2007). Portanto, cada preposição pertencerá a um determinado esquema de imagem, que nada mais é do que uma forma de organização do real, em outras palavras, o modo como imprimimos, através da língua, nossa experiência com o mundo. (JOHNSON, 1987). Nessa configuração, as preposições 'de' e 'para' localizam a figura no objeto de referência através do esquema de imagético de trajetória (ILARI et al. 2008), relacionando, entre si, os significados estabelecidos por elas, individualmente, em uma única representação espacial, correspondendo assim ao fenômeno da polissemia.

No entanto, para supor que exista essa associação entre os significados é preciso saber de que forma ocorre essa relação. O Fenômeno da polissemia coloca em relevância o confronto do nosso senso comum frente à interface do significado de base contido nas palavras e na realidade mais complexa, presente na construção de outros significados (TAYLOR, 2003). Através dessa proposição, conseguimos perceber que a dinâmica da expansão de sentidos é capaz de revelar riqueza e a variedade das capacidades cognitivas que trazemos sobre as situações contextuais mais banais de nosso cotidiano (FAUCONNIER; TURNER, 2003).

\footnotetext{
${ }^{2}$ Tradução livre, no original: "[...] polysemic units are derived from the same lexical source, being the result of processes of extension such as metaphor and metonymy (CROFT; CRUSE, 2004, p. 111).
} 
Esse potencial de significado retrata os processos cognitivos criativos, em que o falante faz conexões conceituais no uso da língua. Para Fauconnier e Turner (2003), a criatividade, presente em nossos contextos discursivos reais, é escondida pela natureza inconsciente e rápida das inúmeras operações cognitivas que contemplam a mais simples de nossas construções de significado.

Um dos aspectos da polissemia deriva do poder de significado potencial, ligado à operação de conceptualização de mundo. Esse fenômeno não é apenas um reflexo do processo natural da evolução da língua, mas principalmente de uma manifestação da adaptação e flexibilidade que o tem falante frente ao seu instrumento de comunicação, a língua. (FAUCONNIER; TURNER, 2003).

Essa expansão de sentidos, referentes a um item lexical, expõe o falante a um problema fundamental, pois enquanto o sistema linguístico é relativamente estreito, o sistema conceitual é vasto, rico e aberto. Desse modo, nos deparamos com problemas referentes à relação entre esses dois sistemas, pois como o sistema linguístico pode ser usado para representar um vasto sistema conceitual se ele é tão restrito? Uma solução para essa questão seria que nós seres humanos possuímos um sistema de forma pronta que viabilize a construção de significados que vão além de uma listagem limitada (idem).

Podemos expandir esse pressuposto para o uso das preposições 'de' e 'para'. Por exemplo, além de seu significado espacial de base, essa categoria lexical representa outras construções de redes conceituais de significado que, em certo nível metafórico, se relacionam. Dizemos então, que essas preposições estão associadas a uma infinidade de mapeamento de sentidos não arbitrários.

Os vários significados estabelecidos por essas preposições podem ser descritos conforme a identificação cognitiva com determinado campo semântico. Por exemplo, no português brasileiro, as preposições 'de' e 'para' podem estabelecer diferentes relações de significado, tais como circunstanciação e também especificação (NEVES, 2011). Por exemplo:

(01) a) Maria me deu esse sapato 'de' couro.

b) João passou na prova 'de' forma duvidosa.

(02) a) Maria trabalhou durante anos 'para' ficar rica.

b) João foi tão irresponsável que seu salário baixou 'para' R $\$ 500$.

Nessa sentença (1a), e de acordo com a interpretação que extraímos de Neves (2011), a preposição 'de' estabelece relação semântica de especificação ao seu objeto de referência 
'couro', enquanto na sentença (1b), a preposição 'de' estabelece relação de circunstância de modo ao objeto referente 'forma duvidosa'. Já na sentença (2a), a preposição 'para' estabelece relação semântica de especificação ao seu objeto referente 'ficar rica', enquanto na sentença (2b), a preposição 'para' estabelece relação de circunstância de finalidade ao referente 'R\$ 500 .

Através dos exemplos acima, e suas respectivas descrições, percebemos que diferentes relações semânticas podem ser interpretadas nos usos das preposições 'de' e 'para'. Com isso, proporemos, na última seção, uma apresentação de algumas relações de sentidos dentro da abordagem localista de Jackendoff (1983), em que podemos visualizar os diferentes significados dessas preposições dentro de campos semânticos específicos.

As preposições são formas lexicais que são relacionadas de modo convencional a significados, formando pares de sentidos armazenados em nosso léxico mental. Nosso léxico mental produz relações de significados associados a uma forma simbólica, dando a entender que essas relações de sentido são dependentes, portanto motivadas (TYLER; EVANS, 2003). No caso das preposições 'de' e 'para', conforme vimos, diferentes significados estão associados a esses itens de conotação espacial, de forma sistemática e não arbitrária. Autores como Tyler e Evans (2003), Jackendoff (1983), Lakoff e Johnson (1980), Fauconnier e Turner (2003) e Pinker (2007) afirmam que podemos fazer uma ligação entre os significados associados a uma mesma forma léxica, pois é possível constituir uma rede semântica sistemática associada a um significado primário de base. As preposições possuem um significado primário de base espacial; portanto, os outros significados que não possuem essa correlação direta, podem ser interpretados metaforicamente de modo que essa configuração seja correlacionada com alguma representação locacional.

Segundo Tyler e Evans (2003), cada significado pertencente a uma rede polissêmica de significados, associados a um item lexical, são produtos de estratégias de inferências, responsáveis por interpretações adicionais e representações mentais. Segundo essas autoras, essas interpretações adicionais, ou extensão de sentidos, nos levam a uma teoria de construção de significado, ou 'integração conceitual'. Para tanto, elas partem dos seguintes pressupostos básicos (idem, p. 3-4):

(i) Os itens lexicais e sintáticos de uma língua subdeterminam as intepretações que são atribuídas regularmente pela ocorrência natural dos enunciados. Podemos interpretar essa afirmação através da pressuposição de que as entradas lexicais servem como porta de entrada para a construção de significado, envolvendo uma elaboração linguística altamente criativa. 
(ii) Para representação do significado, utilizamos inconscientemente um sistema conceitual para a interpretação das formas linguísticas, pois a língua não faz referência direta ao mundo real. Esse sistema contém uma estrutura, que pode ser organizada por conceitos, esquemas imagéticos ou imagens, que refletem e interpretam simbolicamente, o mundo através do conhecimento empírico do falante.

(iii) A estrutura conceitual é uma ferramenta que o falante utiliza para interagir com o mundo, ou seja, o espaço físico que habitamos. Esse mundo exterior nos fornece o substrato necessário para a representação conceitual da língua, e é um substrato sensório-perceptivo que nos permite fazer interpretações abstratas do nosso conhecimento de mundo.

(iv) A língua é um sistema biológico que está em constante evolução. A sincronia da língua revela um fato pontual dentro de um percurso histórico de mudança continua. O estudo factual da língua nos permite compreender o processo de formação de uma rede semântica de um determinado item lexical.

Ao afirmar que as preposições 'de' e 'para' são polissêmicas, estamos corroborando os pressupostos citados acima e pressupondo que os possíveis significados, associados a cada um desses itens lexicais, estão correlacionados espacialmente. Na polissemia, uma forma linguística é ligada, a nível conceitual, com uma rede de significados distintos. Esses significados que estão associados a um único item, nesse caso uma preposição, constituem uma rede semântica de significados possíveis para um mesmo item lexical. Na seção a seguir, veremos como essa polissemia é interpretada em nível espacial por meio do processo de corporificação.

\section{O paralelismo entre experiência corporificada e o esquema imagético de trajetória}

Após a apresentação do fenômeno da polissemia e sua relação com o caráter criativo e evolutivo da língua, retomamos o que falamos acerca de nosso conhecimento de mundo. É através de uma experimentação e interpretação (in)direta de nossa realidade que conseguimos estabelecer uma mediação entre nosso sistema de percepção humano e a construção e representação simbólica dessa vivência através da língua. Quando buscamos interpretar, de maneira conceitual, um item lexical, afirmamos que o mundo real nos fornece o substrato para nossas percepções sensoriais e as conceituações decorrentes dele. Assim, as propriedades de espaço físico do mundo e o nosso conhecimento empírico são fundamentais à cognição humana. Com isso, sugerimos que nossa experiência de mundo é restrita e determinada pela 
natureza dos corpos que temos, implicando na noção da personificação da experiência. Essa experiência é então projetada em nossa língua, e consequentemente, nos fenômenos relacionados a ela, como no caso da polissemia.

Segundo Tyler \& Evans (2003):

A experiência incorporada constitui a noção de que a experiência humana do mundo é mediada pelos tipos de corpos que temos, e portanto é em grande medida determinada pela natureza dos corpos que mediam como nós experimentamos o mundo. Além disso, muitos cientistas cognitivos estão sugerindo que é essa experiência incorporada que dá origem à estrutura conceitual. Ela o faz, foi sugerido, porque nossa percepção do mundo é significativa de várias maneiras para nós como seres humanos. Em outras palavras, nosso mundo, conforme mediado pelo nosso aparato perceptual (nossa fisiologia e arquitetura neural, ou seja, nossos corpos), dão origem à estrutura conceitual, isto é, aos pensamentos e aos conceitos. (p. 23-4. Tradução livre) ${ }^{3}$.

Segundo Johnson (1987), os esquemas de imagem e as projeções que fazemos do mundo são essenciais para o nosso raciocínio e compreensão abstrata. As projeções metafóricas são motivadas por nossas experiências, logo, a experiência deve ser entendida num sentido amplo, na qual incluímos dimensões perceptuais, motoras, emocionais, históricas, sociais e linguísticas. Para ele, "Nossa realidade é moldada pelos padrões do nosso movimento corporal, os contornos da nossa orientação espacial e temporal e as formas de nossa interação com objetos" (p.xix).

Os esquemas imagéticos são estruturas não proposicionais da imaginação. Essas proposições existem como padrões de experiência e conhecimento. Então, “como os esquemas de imagem e suas extensões metafóricas são proposicionais neste sentido especial, constituem grande parte do que chamamos de estrutura de significado e padrões inferencial" (p. 3), indicando que esses esquemas são pautados na experiência humana significativamente organizada, como por exemplo, as estruturas de movimento corporal e interações perceptivas.

Sobre os esquemas imagéticos, Johnson afirma que (1987):

Esquemas típicos terão partes e relações. As partes podem consistir de um conjunto de entidades (tais como pessoas, acessórios, eventos, estados, fontes, objetivos). As relações podem incluir relações causais, sequências temporais, padrões de parte-todo, locações relativas, estruturas agente-paciente, ou relações instrumentais. Normalmente,

\footnotetext{
${ }^{3}$ Embodied experience constitutes the notion that human experience of the world is mediated by the kinds of bodies we have, and hence is in large mea- sure determined by the nature of the bodies which mediate how we experience the world. Moreover, many cognitive scientists are increasingly suggesting that it is this embodied experience that gives rise to conceptual structure. It does so, it has been suggested, because our perception of the world is meaningful in various ways to us as human beings. In other words, our world, as mediated by our perceptual apparatus (our physiology and neural architecture, in short, our bodies), gives rise to conceptual structure, that is, to thought and concepts.
} 
todavia, um esquema dado terá um número pequeno de partes entrando em relações simples (p.28. $)^{4}$.

Como um exemplo, dessas partes e relações, podemos citar o esquema de trajetória, que é o esquema já citado por Ilari et al. (2008), o qual abordamos para a representação espacial das preposições 'de' e 'para do português brasileiro, respectivamente como posições de 'origem' e 'meta'.

Esse tipo de esquema é uma estrutura representativa de uma série de eventos, tais como (JOHNSON, 1987, p. 28): a) andar de uma direção à outra; b) lançar um objeto a um lugar ou a uma pessoas; c) chutar, socar alguém; d) dar alguma coisa à alguém; e c) mudança de estado físico, por exemplo, gelo derretendo. Esses eventos são interpretados metaforicamente como pontos de partida e ponto final. Desse modo, percebemos que "os esquemas imagéticos são mais gerais, abstratos e maleáveis do que imagens ricas; e eles têm partes definidas e relações estruturais que emergem principalmente no nível da nossa percepção ou movimento físico ou corporal.” (ibidem). A seguir, veremos um pouco mais acerca dessa representação espacial, estendida às preposições 'de' e 'para', e a estrutura semântica do esquema imagético de trajetória aparentemente inerente a essas preposições.

\subsection{A representação espacial das preposições}

Como vimos, as preposições 'de' e 'para' indicam movimento no sentido de ponto de origem e ponto final respectivamente. Elas possuem inerentemente uma noção semântica de trajeto; uma trajetória que permite um ponto de partida (preposição 'de') e um ponto final (preposição 'para'). Com o uso, estas preposições passaram da noção de base de trajetória a outras noções, tais como espaço, tempo e finalidade. A preposição 'de' marca as relações de tempo, espaço e muitas outras em que o "valor espacial de procedência pode ou não exercer algum papel” (ILARI et al. 2008 p. 663). Os movimentos, identificados nos processos metafóricos, representam o deslocamento simbólico das preposições 'de' e 'para'. A trajetória embutida neste fluxo apresenta informação espacial, onde cada percurso terá um eixo espacial específico e inconscientemente idealizado pelo falante.

\footnotetext{
${ }^{4}$ Tradução livre, no original: "Typical schemata will have parts and relations. The parts might consist of a set of entities (such as people, props, events, states, sources, goals). The relations might include causal relations, temporal sequences, part-whole patterns, relative locations, agent-patient structures, or instrumental relations. Normally, however, a given schema will have a small number of parts standing in simple relations" (p.28).
} 
Contudo, essa relação espacial não se revela de maneira uniforme, segundo Jackendoff (1983; 1992; 1994) e Pinker (1993; 2007), as relações espaciais entre dois objetos não são expressas simetricamente na língua, inclusive no caso das preposições. Como modo de padronização, eles propõem um formalismo para o conceito geral de movimento, representado como $[\mathrm{GO}(\mathrm{X}, \mathrm{P})]$. Essa fórmula representa o movimento de algum objeto $\mathrm{X}$, também chamado de tema, ao longo de uma trajetória P. Para esses autores, essa representação também é passível para categorias eventivas e estativas, que por sua vez, são situações que acontecem ao longo do tempo. As variáveis $\mathrm{X}$ e $\mathrm{P}$ da fórmula $[\mathrm{GO}]$ pertencem às categorias ontológicas [OBJECT] e [PATH], respectivamente, sendo ilustradas como:

(03) [Event GO ([ object X], [path p]) (JACKENDOFF, 1983, p. 152).

A função [GO] é a representação de uma trajetória de diversos eixos, inclusive o horizontal, como é o caso das preposições 'de' e 'para'. Essa função permite que organizemos a relação de significado que a preposição estabelece entre sua figura e seu objeto de referência, de modo que a representação espacial de base e também a representação espacial conceitual tenham uma interpretação semântica que se aplique a essas duas representações. Desse modo, um esquema imagético de trajetória pode representar uniformemente seu objeto e seu caminho, de forma que a rede de sentidos de uma preposição polissêmica possa ser agrupada em uma mesma estrutura, ou seja, independente da natureza de seu significado (de base ou metafórico), essa fórmula propicia uma interpretação padrão, dentro de uma perspectiva espacial.

A ideia de trajetória, em uma função como [GO], pode ser expressa por um caminhofunção. Nesse percurso, as preposições 'de' e 'para' atribuem sentidos aos seus complementos em um eixo espacial, seja ele de base ou conceitual. No inglês, o caminho-função expresso através da preposição 'from' designa um caminho que começa no objeto de referência, enquanto a preposição 'to' expressa um caminho que termina no objeto de referência (ibidem, JACKENDOFF, 1983, p. 165). O lugar ou ([PLACE]), especificado em uma trajetória P, é apresentado como uma função, onde a preposição, ao determinar um significado, localiza essa relação semântica no objeto de referência (idem, 1994 p. 203). Nesse sentido, o objeto de referência é usado para definir uma região em que se encontra a figura, através da relação de significado estabelecida, por exemplo, na sentença "ela se produziu toda 'para' a festa" a preposição 'para' estabelece relação semântica de finalidade para o objeto de referência 'a 
festa' e, interpretando conceitualmente essa relação, a preposição localiza a figura, representada pelo evento 'se produzir', no objeto de referência 'a festa'. Fazendo um paralelo conceitual, o ponto de referência 'a festa', enquanto finalidade atribuída pelo predicador, pode representar um ponto final de uma trajetória conceitual.

Jackendoff (1992) expõe a grandeza das diferentes relações espaciais que as preposições podem expressar. Segundo ele, elas são naturalmente polissêmicas. Por serem polissêmicas, as preposições apresentam restrições entre a figura e seu objeto de referência quando expressam relações espaciais. Para a definição de relações espaciais, alguns fatores devem ser respeitados, tais como: a assimetria entre a figura e objeto de referência, responsável pelos parâmetros básicos das relações espaciais; a descrição da referência do objeto; o objeto figura; a região ocupada pelo objeto de referência. Essa assimetria segue os princípios de organização espacial que requerem que um objeto ou evento seja localizado relativamente a outro objeto ou evento, para que assim a relação de significado seja estabelecida.

Dentro da classe dos significados dos sintagmas preposicionais, deve-se fazer uma distinção entre [PLACES] e [PATHS]. Dento de uma estrutura de evento, [PLACES] projeta um ponto ou região que é ocupado por [THING]. Já [PAHT] consiste de um caminho-função e um objeto de referência, como expresso pelo sintagma "para o chão" (JACKENDOFF, 1983, p. 163). Os sintagmas preposicionais correspondem aos conceitos de lugar de maneiras diferentes. Cada função de lugar impõe restrições conceituais sobre a natureza do objeto de referência. Esses objetos se apresentam na língua como restrições selecionais para as preposições que lhes fazem correspondência. Desse modo, as preposições não são empregadas aleatoriamente, pois existem restrições quanto à delimitação das relações de significados. Por exemplo, nas sentenças "Ele riu 'de' mim" e "Ele riu "para' mim", a depender da intenção do falante, a escolha da preposição determinará a relação de significado específica. Nos exemplos citados, ao atribuir a preposição 'de' ou 'para' ao objeto de referência 'mim', sentidos diferentes são compreendidos. Essa restrição imposta pelo objeto de referência refletirá diretamente na natureza dos significados que essas preposições estabelecerão. Na sentença "Ele riu 'de' mim”, a preposição 'de' denota um sentido de especificação, em que a origem da ação de 'rir' é proveniente do objeto de referência 'mim'; já na sentença “Ele riu 'para' mim”, a preposição 'para' denota um sentido de direção, em que a meta da ação 'rir' também é proveniente do objeto de referência 'mim'. 
A função [PATH] ou função de trajetória pode ser dividida em três grandes tipos quando confrontados com relação a um dado percurso, retratando a direção a um objeto ou local de referência (JACKENDOFF, 1983, p. 165). Como exemplo do primeiro tipo, chamado “bounded paths”, podemos citar o caminho 'fonte' ou 'origem' do significado básico das preposições. Jackendoff (1983) cita os exemplos das preposições do inglês 'from' e 'to', formas correlatas do 'de' e do 'para' do português brasileiro, para demonstrar a relação de significado espacial dessas preposições. Por exemplo:

(04) (a) “John ran 'from' the house” (ibidem, p. 165).

(a') João correu da casa.

(b) “John ran 'to' the house” (ibidem, p. 165).

(b') João correu para a casa.

Observe que, nas sentenças (a) e (b), as preposições 'from' e 'to' estabelecem relações de significado espacial de base, respectivamente ponto de origem e ponto final para o objeto de referência "house" (p. 165). O objeto de referência ou lugar são pontos de extremidade do início de um caminho de origem e o fim de um caminho de meta.

Um segundo tipo de trajetória (direction) é uma extensão do caminho para alguma distância não especificada. No português brasileiro, podemos citar sentenças como "João correu 'para' casa”, em que 'casa' não é necessariamente o ponto final, mas sim a direção de um percurso, no sentido de correr até a 'casa', sem, no entanto, chegar e estar no objeto de referência 'casa'. Um terceiro tipo de caminho é o de rota, em que o lugar ou objeto de referência está relatado no ponto interior da trajetória. Como exemplo desse tipo de caminho, temos a sentença: “O rato correu pela garagem”, em que a preposição 'pela' indica o ponto medial de um percurso.

Na relação espacial de trajetória, algumas preposições especificam, de modo real ou abstrato, o movimento entre a figura e um objeto de referência. Alguns grupos de preposições possuem eixos específicos que retratam determinados movimentos (JACKENDOFF, 1992). No português brasileiro, conforme apresentamos, as preposições também se distribuem em eixo. No que concerne à rota desses movimentos, por exemplo, Ilari et al. (2008) apontam que as preposições 'de' e 'para' são representadas em um eixo espacial horizontal, ou seja, o movimento representa um deslocamento em linha reta, em que a preposição 'de' ocupa lugar de origem e a preposição 'para' meta. Jackendoff (1983) apresenta, como exemplo, as preposições 'from' e 'to', ambas opostas em uma trajetória linear:

(05) (a) 'The train came from inside the Soviet Union" (JACKENDOFF, 1983 p.116 
(a') O trem veio de dentro da União Soviética.

(b) "The bird flew to the house" (ibidem, p.116).

(b’) O pássaro voou para casa.

Na sentença (a), a preposição 'from', forma correlata da preposição 'de' do português brasileiro, denota o ponto de origem de uma trajetória, que começa na região em questão. $\mathrm{Na}$ sentença (b), a preposição 'to', forma correlata de 'para', expressa uma trajetória que termina na região. Desse modo, os exemplos (a) e (b) são construções que expressam um caráter espacial inerente ao significado das preposições.

Ao propor que as preposições apresentam caráter espacial, Jackendoff (1983; 1992) traz para sua discussão a complexidade do comportamento desses itens lexicais, ou seja, a polissemia. Algumas preposições envolvem configurações espaciais de base, ao relacionar uma figura a um objeto de referência. No entanto, muitas delas não apresentam esse comportamento prototípico de representação espacial. Todavia, propomos que o significado espacial, implícito no uso das preposições 'de' e 'para', pode ser interpretado metaforicamente, apresentando, então, ambiguidade lexical. Esses significados metafóricos podem ser relacionados com os significados básicos das preposições, pois, a partir do momento em que identificamos, nessa rede de significados, traços semânticos semelhantes, sugerimos que as preposições podem, sim, ser itens polissêmicos.

Embora a polissemia das preposições não seja tão evidente como em alguns nomes ou verbos, é possível, através da experiência corporificada e da criação de esquemas imagéticos, identificar que os significados das preposições 'de' e 'para' podem ser relacionados em uma trajetória espacial conceitual. Dessa maneira, visando organizar as relações entre os significados atribuídos pelas preposições 'de' e 'para', recorremos à "Hipótese de Relação Temática" (JACKENDOFF, 1983). Essa hipótese nos permite propor uma sistematização na qual cada relação de sentido seja enquadrada em cada referido campo semântico.

\subsection{As representação espacial das preposições nos campos semânticos: identificacional, possessional e temporal.}

Após os pressupostos apresentados acerca da polissemia da preposição, da experiência corporificada, e da representação espacial, passamos agora à organização dessa representação, ou seja, como podemos organizamos os sentidos polissêmicos das preposições 'de' e 'para', 
de modo que possamos visualizar o seu sentido abstrato locacional. Mais uma vez, usaremos a abordagem localista de Jackendoff $(1983,1999)$ para a compreensão das redes de significados dessas preposições. A princípio, o sentido de base espacial é aquele em que conseguimos interpretar o sentido de localização sem, contudo, recorrer a uma interpretação metafórica, por exemplo: 'Eu fui 'de' São Paulo 'para' Roraima. Nessa sentença, percebemos que os sintagmas preposicionais apresentam de fato um sentido relacionado a um local de base, ou seja, ponto de partida (São Paulo) e ponto final (Roraima). No entanto, esse sentindo locacional pode ser estendido para outros campos semânticos que não apresentem uma localização básica.

Jackendoff (1983) adaptou, à sua maneira, a teoria localista de Gruber (1976) acerca da organização em campos semânticos de conceitos de localização e movimento. Para Jackendoff (1983), esses conceitos são abstraídos e generalizados para muitos campos semânticos, que nada mais são que extensões de um campo semântico espacial. No caso das preposições, o autor afirma que esses itens podem aparecer em diferentes campos semânticos, apresentando uma relação de localização entre si. Essa abordagem localista, como já mencionamos, recebeu o nome de 'Hipótese da relação temática'.

Nesse trabalho, em função da delimitação do tema e do formato do artigo, apresentaremos apenas três desses campos semânticos para exemplificar essa categorização das relações de significados atribuídos por esse par de preposição, a saber: identificacional, possessional e temporal. Acreditamos que a proposta de apresentação desses campos serve como modelo descritivo para outros campos; assim, escolhemos apenas esses três para exemplificar como essa categorização funciona. Desse modo, procuraremos estabelecer ligações entre esses três campos e os significados das preposições 'de' e 'para'. Os campos semânticos que apresentaremos a seguir possuem a mesma estrutura semântica, ou seja, aquela que correspondente ao predicado GO de trajetória espacial: [EVENT GO ([ object X], [path p]) JACKENDOFF, 1983, p. 152). Abaixo, os campos semânticos abordados:

\subsubsection{Campo semântico identificacional}

Nesse campo semântico, algumas preposições podem se apresentar como marcador identificacional de locação. Em seu 'pseudoespaço', [THINGS] aparecem como figura, [THING TYPES] a [PROPERTIES] aparecem como objeto de referência. A especificação de um objeto de referência faz o papel de localização, ou seja, a figura, ao especificar uma 
caraterística do objeto de referência, também localiza-o conceitualmente (ibidem, p. 194).

Como exemplos desse campo para o uso das preposições 'de' e 'para', temos respectivamente as seguintes sentenças:

(06) a) Maria morreu 'de' câncer.

a) O salário da Maria subiu 'para' 15 mil.

Nas sentenças acima, as preposições pertencem ao campo identificacional, no entanto, conseguimos fazer uma extensão desse sentido para o campo espacial de base. Na sentença (5a), a preposição localiza a figura, representada pelo evento 'morrer', no objeto de referência 'câncer', em que 'câncer' representa a origem da "causa da morte" estabelecida pela preposição. Já na sentença (5b), o sintagma 'para 15 mil', conceptualizamos que em uma dada trajetória abstrata, o salário tinha um valor x que aumento para valor y, ou seja, houve um deslocamento metafórico, em que 'para 15 mil', representa um ponto final em uma trajetória espacial simbólica.

\subsubsection{Campo semântico possessional}

Assim como no campo semântico Temporal, no campo semântico Possessional, as preposições também estabelecem para o seu objeto de referência um significado 'pseudoespacial'. Nesse 'pseudoespaço', [THINGS] aparecem como figura e também como objeto de referência. Ser possuidor alienavelmente desempenha o papel de locação, ou seja, 'y possui x', que é o paralelo conceptual do sentindo espacial 'x está em y' (JACKENDOFF, 1983, p. 192). Apresentamos como exemplos desse campo, as seguintes sentenças com o uso das preposições 'de' e 'para', respectivamente:

(07) a) Essa boneca era 'de' todas as crianças da creche.

a) O prêmio da loteria foi 'para' a mais sortuda das mulheres.

Na sentença (6a), visualizamos um sentindo espacial. Quando imaginamos uma trajetória em linha na qual, o sintagma 'de todas as crianças da creche' representa um possuidor, ou seja, a figura 'essa boneca' pertencia originalmente às 'crianças da creche', ou seja, nessa sentença, o sintagma preposicional representa um ponto de origem em uma análise localista, no qual a preposição localiza como ponto de partida a figura 'boneca' no objeto de referência 'todas as crianças da creche'. Visualizamos esse sentindo espacial também na sentença (6b), em que o sintagma 'para a mais sortuda das mulheres' representa um ponto final da trajetória, pois conceptualizamos abstratamente que a figura 'o prêmio da loteria' se deslocou até um 
ponto final, ou seja, 'para a mais sortuda das mulheres' que, por sua vez, representa a região ocupada pela figura.

\subsubsection{Campo semântico temporal}

Nesse campo semântico, as relações que as preposições estabelecem para o seu objeto de referência definem uma dimensão denominada 'pseudoespacial', que corresponde a região ocupada por este objeto Jackendoff (1983), em que [EVENTS] e [STATES] podem aparecer como figura, e [TIMES] pode aparecer como objeto de referência. Na relação de significado, em um campo semântico Temporal, o tempo de ocorrência desempenha o papel de localização. Desse modo, a localização ou movimento temporal podem ser interpretados como localização e movimento espacial. Observemos as sentenças em que 'de' e 'para' pertencem ao campo semântico temporal, como sentido abstrato locacional:

(08) Esse ano voou principalmente 'de' maio 'para' dezembro.

$\mathrm{Na}$ sentença acima, as preposições 'de' e 'para' também tem seus sentidos estendidos para a representação espacial. No sintagma 'de maio', conseguimos conceptualizar como um ponto inicial de uma trajetória, ou seja, a preposição "de" localiza o evento 'esse ano voou' em um ponto de partida, metaforicamente interpretada como espacial. $\mathrm{O}$ mesmo acontece com a preposição 'para', a qual localiza o mesmo evento, porém, em um ponto final, ou seja, no mês 'dezembro'.

Em suma, como pudemos ver através dos exemplos analisados acima, conseguimos fazer uma interpretação abstrata dos campos semânticos Identificacional, Possessional e Temporal, pois percebemos que é possível interpretar metaforicamente os significados das preposições nas sentenças em (05), (06) e (07) como extensões de um significado de base espacial, no qual as preposições 'de' e 'para' correspondem a significados relacionados a ponto de origem e ponto final respectivamente. Com isso, ao estender a hipótese de Jackendoff $(1983$; 1992) para o uso dessas duas preposições, podemos identificar as relações de significado dos campos semânticos não espaciais, com uma representação conceitual localista de trajetória, inerente a essas duas preposições. Ao encontrarmos essas relações, acreditamos que as preposições 'de' e 'para', além de completarem o sentido do predicado, são itens polissêmicos, pois seus diferentes significados podem estar relacionados entre si através de uma representação espacial conceitual de trajetória. 


\section{Considerações finais}

Nesse trabalho, não exploramos todos os campos espaciais possíveis e existentes e nem todas as relações de significados atribuídos pelas preposições 'de' e 'para', pois como fato, são muitas. Nosso objetivo central foi descrever a natureza polissêmica e esquemática do par de preposições. Logicamente, haverá usos em que uma compreensão localista possa ser colocada em questão; contudo, de modo genérico, elas possuem prototipicamente uma função espacial, originalmente estabelecida.

Conforme desenrolar das análises, traçamos um percurso em torno do comportamento esquemático das preposições 'de' e 'para' do português brasileiro e do caráter polissêmico dos significados que atribuem. Além de serem preposições de maior ocorrência nessa língua, o seu uso está intimamente ligado à cognição humana. Elas atuam como operadores de predicação, relacionando uma figura a um objeto de referência, estabelecendo uma relação de significado com essa predicação.

Esses sentidos são distintos, no entanto, em uma interpretação mais abstrata, os significados estabelecidos pelas preposições 'de' e 'para' estão relacionados espacialmente. A expansão de sentidos dessa categoria lexical é uma caraterística inerente ao fenômeno da polissemia, que por sua vez está intimamente ligada à experiência corporificada do falante. Esse conhecimento permite que o indivíduo construa inconscientemente esquemas imagéticos relacionados às experiências sociais, físico-motoras e culturais, motivadas por suas vivências de mundo e consequentemente inseridos no léxico da língua.

O esquema que abordamos nesse trabalho foi o esquema de trajetória, em que a preposição 'de' representa um ponto de origem e a preposição 'para' um ponto final. Nele, um número considerável de significados, que essas preposições estabelecem, podem ser representados nessa trajetória, sejam eles de base ou não. Para tanto, Jackendoff (1983, 1999) adaptou uma abordagem localista, denominando-a de 'Hipótese da relação temática' em que os diversos sentidos das preposições 'de' e 'para' podem ser relacionados ao significado de base espacial dessas mesmas preposições, através dos campos semânticos Identificacional, Possessional e Temporal.

\section{Referências}

CASTILHO, A. Nova gramática do português brasileiro. São Paulo: Contexto, 2010. 
CROFT, W.; CRUSE, D.A. Cognitive Linguistics. New York: Cambrige, 2004.

FAUCONNIER, G., TURNER, M. Polysemy and conceptual blending. In: NERLICH, B. et al. (Org). Polysemy flexible patterns of meaning in Mind and Language. New York: Mouton de Gruyter, 2003. pp. 79-94.

ILARI, R., CASTILHO, A.T., ALMEIDA, M.L.L., KLEPPA, L.A., BASSO, R.M. A preposição. In: ILARI, R e NEVES, M.H.M (ORGS). Gramática do português culto falado no Brasil:. volume 2 : classes de palavras e processos de construção. Campinas, SP: UNICAMP, 2008.

GRUBER, S. "Studies in Lexical Relations." Ph.D. dissertation, MIT. Reprinted as part of Lexical Structures in Syntax and Semantics. Amsterdam: North-Holland (1976).

JACKENDOFF, R. Consciousness and the Computational Mind. Cambridge, MA: MIT Press, 1994.

Press, 1992.

Languages of the Mind: Essays on Mental Representation. Cambridge, MA: MIT . Semantics and Cognition. Cambridge, MA: MIT Press, 1983.

JOHNSON, M. The body in the mind: the bodily basis of meaning, imagination, and reason. Chicago: University of Chicago, 1987.

LAKOFF, G.; JOHNSON, M. Metaphors we live by. Chicago: The University of Chicago Press, 1980.

NEVES, M. H. de M.. Gramática de usos do português. São Paulo: Editora UNESP, 2011.

Learnability and cognition. Cambridge: MIT Press, 1993.

PINKER, S. Do que é feito o pensamento: a língua como janela para a natureza humana. São Paulo: Companhia das letras, 2007.

RICOEUR, P. A metáfora viva. 2. São Paulo: Loyola, 2005.

TAYLOR, J. Cognitive models of polysemy. In: NERLICH, B. et al. (Org). Polysemy flexible patterns of meaning in Mind and Language. New York: Mouton de Gruyter, 2003. pp. 31-48.

TYLER, A.; EVANS, V. The Semantics of English Prepositions: Spatial Scenes, Embodied Meaning and Cognition. Cambrige: University Press, 2003. 